\title{
Commentary: Rifabutin Resistance Associated with Double Mutations in rpoB Gene in Mycobacterium tuberculosis Isolates
}

\author{
Sandeep Sharma ${ }^{1,2}$ and Noton K. Dutta ${ }^{3 *}$ \\ ${ }^{1}$ Department of Microbiology, Perelman School of Medicine, University of Pennsylvania, Philadelphia, PA, United States, \\ ${ }^{2}$ Department of Biochemistry and Molecular Biology, Thomas Jefferson University, Philadelphia, PA, United States, \\ ${ }^{3}$ Department of Medicine, Center for Tuberculosis Research, Johns Hopkins University School of Medicine, Baltimore, MD, \\ United States
}

Keywords: tuberculosis, rifabutin, RpoB, double mutations, rifampicin

\section{A commentary on}

Rifabutin Resistance Associated with Double Mutations in rpoB Gene in Mycobacterium tuberculosis Isolates

by Jing, W., Pang, Y., Zong, Z., Wang, J., Guo, R., Huo, F., Jiang, G., Ma, Y., Huang, H., and Chu, N. (2017). Front. Microbiol. 8:1768. doi: 10.3389/fmicb.2017.01768

OPEN ACCESS

Edited by:

Miklos Fuzi,

Semme/weis University, Hungary

Reviewed by: Anthony Baughn,

University of Minnesota, United States

*Correspondence:

Noton K. Dutta ndutta1@jhmi.edu

Specialty section: This article was submitted to Antimicrobials, Resistance and

Chemotherapy,

a section of the journal

Frontiers in Microbiology

Received: 19 October 2017 Accepted: 06 November 2017 Published: 27 November 2017

Citation:

Sharma S and Dutta NK (2017)

Commentary: Rifabutin Resistance Associated with Double Mutations in

rpoB Gene in Mycobacterium tuberculosis Isolates.

Front. Microbiol. 8:2274

doi: 10.3389/fmicb.2017.02274
Rifabutin (RFB), a member of rifamycin family, was approved by the FDA in 1992 and was recognized in 2009 as an essential medicine by WHO (World Health Organization, 2011; Crabol et al., 2016). Rifabutin is recommended for tuberculosis (TB) [including Mycobacterium avium complex (MAC)] treatment and has been used in patients coinfected with HIV/AIDS (Rukasha et al., 2016). Rifabutin exhibits fewer drug-drug interactions than rifampicin (RIF) and induces cytochrome $450\left(\mathrm{CYP}_{3 \mathrm{~A} 4}\right)$ to a much lower degree than RIF (Zhang et al., 2011; Dutta and Karakousis, 2015). It is associated with lower MIC values than RIF for MAC, Mycobacterium tuberculosis (Mtb), Mycobacterium leprae and other non-tuberculous mycobacteria and it yields higher MIC values against actively growing Mycobacteria (Van Ingen et al., 2010; Aziz et al., 2017). Rifabutin is quite stable in stomach acid ( $\mathrm{pH} \mathrm{2-8)} \mathrm{and} \mathrm{antacids,} \mathrm{and} \mathrm{it} \mathrm{is} \mathrm{more} \mathrm{lipophilic} \mathrm{in} \mathrm{nature}$ than RIF and accordingly associated with much higher uptake in tissue and therefore distribution (Blaschke and Skinner, 1996).

Rifampicin and RFB both inhibit $M t b$ by acting on the $\beta$-subunit of the $r p o B$ gene of DNA-dependent RNA polymerase (Dutta and Karakousis, 2017). It is important to characterize $r p o B$ gene mutations and their connection with RIF and RFB resistance to better understand the phenotypic and molecular results noted in clinical settings. Rifampin Resistance-Determining Region (RRDR) in the $r p o B$ gene in $M t b$ is significantly associated with mutations from codons 507-533 of $r p o B$, within an 81 bp fragment of $r p o B$ gene. A high level of rifamycin resistance (RIF and RFB) is exhibited by strains with mutations in codons 526 and 531 [Minimum Inhibitory Concentration (MIC) of RIF $>160 \mu \mathrm{g} / \mathrm{ml}$; RFB > $5 \mu \mathrm{g} / \mathrm{ml}$ ] (Jamieson et al., 2014). However, there are some other mechanisms that also contribute to RIF resistance to $M t b$. Approximately $5 \%$ of $M t b$ RIF resistance isolates exhibited an unknown mechanism for resistance, suggesting that some alternative mechanism-such as the upregulation of the transmembrane protein (efflux pumps), reduced cell wall permeability, or inactivation of drugs - was at play (Louw et al., 2009).

The cross resistance to RIF and RFB is very common. Roughly $25 \%$ of RIF resistance isolates with a mutation in codon 516 remain susceptible phonetically to RFB at a critical concentration of 
$0.5 \mu \mathrm{g} / \mathrm{ml}$ (Uzun et al., 2002; Senol et al., 2005; Van Ingen et al., 2011). Rifabutin has been suggested to be rational alternative to treat MDR-TB and XDR TB, particularly associated with $r p o B$ mutation (Sirgel et al., 2013).

Jing et al. (2017) investigated cross-resistance between RIF and RFB among clinical isolates of $\mathrm{M} t b$ from the National Tuberculosis Clinical Laboratory, Beijing Chest Hospital, China. The study considered 256 isolates and attempted to establish a relationship between $\mathrm{MIC}$ and $r p o B$ gene mutations. The majority of isolates exhibited a single mutation in the $r p o B$ gene, followed by a double mutation or no mutation in the $r p o B$ gene in the clinical isolates. Therefore, a specific mutation in the $r p o B$ gene was associated with RIF resistance and RFB susceptibility (Jamieson et al., 2014).

The data of Jing et al. (2017) also emphasize the use of RFB in the place of RIF because MIC for all of the resistant isolates exhibited lower RFB MIC compared with RIF. The data are consistent with previous findings (Jamieson et al., 2014; Berrada et al., 2016), which have demonstrated that the rpoB mutations S531L, H526D, H526R, H526C, and D516V confer phenotypical high-level resistance to both RIF and RFB; amino acid substitution at codons L511P, D516G/Y, S522L, H526Y/L/D/N, S531Q, and L533P was associated with phenotypic resistance to RIF and susceptibility to RFB (Rukasha et al., 2016). Roughly $5 \%$ of cases of $M t b$ resistance to RIF did not exhibit any mutation in the $r p o B$ gene, suggesting some alternative mechanism for RIF resistance or a mutation in another part of the $r p o B$ gene. Mutations in codon 511, 515,522 , and 533 of $r p o B$ were associated with a low level of resistance, and the overexpression of certain transmembrane proteins ( $R v 1258 C$ and $R v 2136 c$ in the presence of RIF) were also associated with RIF resistance (Siddiqi et al., 2004; Sharma et al., 2010).

There have been reports that $r p o B$-independent RIF resistance in $M t b$ is due to overexpression of transmembrane proteins (efflux proteins) and can be countered by using EPIs (De Vos et al., 2013) A large number of studies conducted by different groups have focused on the combination of existing drugs with some natural molecules to lower the MIC value in vitro. Since RFB has exhibited reduced toxicity and other pharmacological advantages over RIF in HIV/AIDS patients, it should be tested

\section{REFERENCES}

Ali, A., Hasan, Z., Mcnerney, R., Mallard, K., Hill-Cawthorne, G., Coll, F., et al. (2015). Whole genome sequencing based characterization of extensively drug-resistant Mycobacterium tuberculosis isolates from Pakistan. PLoS ONE 10:e0117771. doi: 10.1371/journal.pone.0117771

Aziz, D. B., Low, J. L., Wu, M.-L., Gengenbacher, M., Teo, J. W. P., Dartois, V., et al. (2017). Rifabutin Is Active against Mycobacterium abscessus Complex. Antimicrob. Agents Chemother. 61:e00155-17. doi: 10.1128/AAC.00 155-17

Berrada, Z. L., Lin, S. Y., Rodwell, T. C., Nguyen, D., Schecter, G. F., Pham, L., et al. (2016). Rifabutin and rifampin resistance levels and associated rpoB mutations in clinical isolates of Mycobacterium tuberculosis complex. Diagn. Microbiol. Infect. Dis. 85, 177-181. doi: 10.1016/j.diagmicrobio.2016. 01.019 in combination with molecules reported to increase drug efficacy and possess potential immunomodulatory activity in a murine model.

The conventional drug susceptibility assay can provide appropriate results for detecting $r p o B$ mutation, but the method is time consuming: it takes several weeks to generate a susceptibility profile. This prolonged duration can result in a delay in treatment and the generation of drug resistance over time. Furthermore, there have been reports about the compensatory mutation in $r p o A$ and $r p o C$ regions that improve the fitness cost in RIF-resistant Mtb strains (De Vos et al., 2013; Ali et al., 2015). Other advanced methods (sequencing the RRDR, GeneChip, Proteomics) and bioinformatics tools give new hope for the detection of drug-resistant TB in clinical settings, but all these tools are expensive and are out of reach of many TB management programs across the world.

The current study is interesting and will help in epidemiology studies about the burden of RIF and RFB resistance against $M t b$ in China and many other high TB burden countries. Furthermore, studies of this kind will be useful for developing combination treatment regimen effective against mycobacterial diseases based on rpoB gene mutations (Deshpande et al., 2017). Additional studies will yield a better understanding of mutations in $r p o B$ gene and facilitate the analysis of drug resistance to RFB associated with double mutations in the $r p o B$ gene.

\section{AUTHOR CONTRIBUTIONS}

SS and ND have made substantial, direct and intellectual contribution to the work, critically reading an earlier version of this manuscript and approved it for publication.

\section{FUNDING}

Johns Hopkins University Center for AIDS Research (P30AI094189) Scholar Grants for Faculty Development, Institute for Clinical and Translational Research (UL1 TR 001079) Nexus Biomarkers and Diagnostic award, and AIDS Clinical Trials Group supplemental (UM1 AI68636-12) to ND. Creative Biomedical Research Institute, Philadelphia, for financial support to SS.
Blaschke, T. F., and Skinner, M. H. (1996). The clinical pharmacokinetics of rifabutin. Clin. Infect. Dis. 22(Suppl. 1), S15-S21; discussion S21-12. doi: 10.1093/clinids/22.Supplement_1.S15

Crabol, Y., Catherinot, E., Veziris, N., Jullien, V., and Lortholary, O. (2016). Rifabutin: where do we stand in 2016? J. Antimicrob. Chemother. 71, 1759-1771. doi: 10.1093/jac/dkw024

Deshpande, D., Srivastava, S., Pasipanodya, J. G., Lee, P. S., and Gumbo, T. (2017). A novel ceftazidime/avibactam, rifabutin, tedizolid and moxifloxacin (CARTM) regimen for pulmonary Mycobacterium avium disease. J. Antimicrob. Chemother. 72, i48-i53. doi: 10.1093/jac/dkx307

De Vos, M., Müller, B., Borrell, S., Black, P. A., Van Helden, P. D., Warren, R. M., et al. (2013). Putative compensatory mutations in the rpoC gene of rifampinresistant Mycobacterium tuberculosis are associated with ongoing transmission. Antimicrob. Agents Chemother. 57, 827-832. doi: 10.1128/AAC.01 541-12 
Dutta, N. K., and Karakousis, P. C. (2015). Can the duration of tuberculosis treatment be shortened with higher dosages of rifampicin? Front. Microbiol. 6:1117. doi: 10.3389/fmicb.2015.01117

Dutta, N. K., and Karakousis, P. C. (2017). "Mechanisms of action and resistance of the antimycobacterial agents," in Antimicrobial Drug Resistance: Mechanisms of Drug Resistance, Vol. 1, eds D. L. Mayers, J. D. Sobel, M. Ouellette, K. S. Kaye, and D. Marchaim (Cham: Springer International Publishing), 359-383.

Jamieson, F. B., Guthrie, J. L., Neemuchwala, A., Lastovetska, O., Melano, R. G., and Mehaffy, C. (2014). Profiling of rpoB mutations and MICs for rifampin and rifabutin in Mycobacterium tuberculosis. J. Clin. Microbiol. 52, 2157-2162. doi: 10.1128/JCM.00691-14

Jing, W., Pang, Y., Zong, Z., Wang, J., Guo, R., Huo, F., et al. (2017). Rifabutin resistance associated with double mutations in rpoB gene in Mycobacterium tuberculosis isolates. Front. Microbiol. 8:1768. doi: 10.3389/fmicb.2017. 01768

Louw, G. E., Warren, R. M., Gey Van Pittius, N. C., Mcevoy, C. R., Van Helden, P. D., and Victor, T. C. (2009). A balancing act: efflux/influx in mycobacterial drug resistance. Antimicrob. Agents Chemother. 53, 3181-3189. doi: 10.1128/AAC.01577-08

Rukasha, I., Said, H. M., Omar, S. V., Koornhof, H., Dreyer, A. W., Musekiwa, A., et al. (2016). Correlation of rpoB mutations with minimal inhibitory concentration of rifampin and rifabutin in Mycobacterium tuberculosis in an HIV/AIDS Endemic Setting, South Africa. Front. Microbiol. 7:1947. doi: $10.3389 /$ fmicb. 2016.01947

Senol, G., Erbaycu, A., and Ozsöz, A. (2005). Incidence of cross resistance between rifampicin and rifabutin in Mycobacterium tuberculosis strains in Izmir, Turkey. J. Chemother. 17, 380-384. doi: 10.1179/joc.2005.17.4.380

Sharma, S., Kumar, M., Sharma, S., Nargotra, A., Koul, S., and Khan, I. A. (2010). Piperine as an inhibitor of Rv1258c, a putative multidrug efflux pump of Mycobacterium tuberculosis. J. Antimicrob. Chemother. 65, 1694-1701. doi: $10.1093 / \mathrm{jac} / \mathrm{dkq} 186$

Siddiqi, N., Das, R., Pathak, N., Banerjee, S., Ahmed, N., Katoch, V. M., et al. (2004). Mycobacterium tuberculosis isolate with a distinct genomic identity overexpresses a tap-like efflux pump. Infection 32, 109-111. doi: 10.1007/s15010-004-3097-x

Sirgel, F. A., Warren, R. M., Böttger, E. C., Klopper, M., Victor, T. C., and Van Helden, P. D. (2013). The rationale for using rifabutin in the treatment of MDR and XDR tuberculosis outbreaks. PLOS ONE 8:e59414. doi: 10.1371/journal.pone.0059414

Uzun, M., Erturan, Z., and Ang, O. (2002). Investigation of cross-resistance between rifampin and rifabutin in Mycobacterium tuberculosis complex strains. Int. J. Tuberc. Lung Dis. 6, 164-165.

Van Ingen, J., Aarnoutse, R., De Vries, G., Boeree, M. J., and Van Soolingen, D. (2011). Low-level rifampicin-resistant Mycobacterium tuberculosis strains raise a new therapeutic challenge. Int. J. Tuberc. Lung Dis. 15, 990-992. doi: 10.5588/ijtld.10.0127

Van Ingen, J., Van Der Laan, T., Dekhuijzen, R., Boeree, M., and Van Soolingen, D. (2010). In vitro drug susceptibility of 2275 clinical nontuberculous Mycobacterium isolates of 49 species in The Netherlands. Int. J. Antimicrob. Agents 35, 169-173. doi: 10.1016/j.ijantimicag.2009.09.023

World Health Organization (2011). The selection and use of essential medicines. World Health Organ. Tech. Rep. Ser. 965, i-xiv, 1-249.

Zhang, J., Zhu, L., Stonier, M., Coumbis, J., Xu, X., Wu, Y., et al. (2011). Determination of rifabutin dosing regimen when administered in combination with ritonavir-boosted atazanavir. J. Antimicrob. Chemother. 66, 2075-2082. doi: $10.1093 /$ jac/dkr266

Conflict of Interest Statement: The authors declare that the research was conducted in the absence of any commercial or financial relationships that could be construed as a potential conflict of interest.

Copyright (c) 2017 Sharma and Dutta. This is an open-access article distributed under the terms of the Creative Commons Attribution License (CC BY). The use, distribution or reproduction in other forums is permitted, provided the original author(s) or licensor are credited and that the original publication in this journal is cited, in accordance with accepted academic practice. No use, distribution or reproduction is permitted which does not comply with these terms. 